
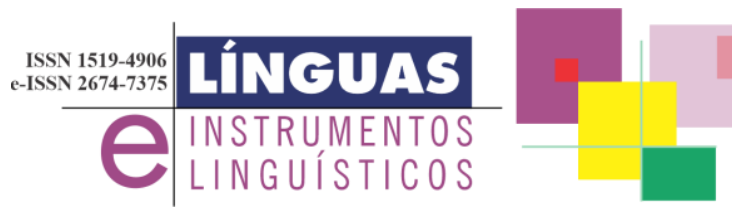

DOI: $10.20396 /$ lil.v23i46.8661675

\title{
O COTIDIANO NA HISTÓRIA DAS IDEIAS LINGUÍSTICAS
}

\section{THE EVERYDAY LIFE IN THE HISTORY OF LINGUISTIC IDEAS}

\author{
Ana Cláudia Fernandes Ferreira* \\ UNICAMP
}

Resumo: O presente trabalho busca contribuir para uma teorização discursiva sobre a questão do cotidiano na história das ideias linguísticas. Para isso, empreendo diálogos e debates teóricos com estudos de Michel de Certeau, Michel Pêcheux, Sylvain Auroux e Eni Orlandi.

Palavras-chave: Cotidiano, História das ideias linguísticas, Análise de discurso.

Abstract: This work aims to contribute to a discursive theorization on the issue of everyday life in the history of linguistic ideas. For this, I undertake dialogues and theoretical debates with studies of Michel de Certeau, Michel Pêcheux, Sylvain Auroux and Eni Orlandi.

Keywords: Every day life, History of linguistics ideas, Discourse analysis.

\section{Considerações iniciais}

O presente trabalho foi elaborado a partir de um conjunto de questões que minhas investigações vêm demandando formular, no âmbito de uma perspectiva discursiva da história das ideias linguísticas, a respeito dos saberes linguísticos. Essas questões estão ligadas, de modo geral, a um profundo interesse pelos processos de constituição, divisão e hierarquização de saberes. Mais recentemente, esse interesse se voltou para uma investigação a respeito dos saberes (sobre) a(s) língua(s) do/no Brasil em seus modos de circulação 
cotidiana, produzidos em uma relação tensa em contraditória com saberes linguísticos especializados ligados a instituições do saber que os autorizam e legitimam (como os domínios da gramática, da linguística e da literatura) ${ }^{1}$. Isso me levou ao desenvolvimento de pesquisas sobre o que venho chamando de saberes linguísticos cotidianos $^{2}$. A partir daí, no decorrer desses trabalhos, uma necessidade de indagar sobre a materialidade discursiva do cotidiano foi se tornando cada vez mais necessária, fazendo com que o cotidiano se colocasse como uma questão incontornável para o desenvolvimento de minhas pesquisas.

Quando algo se torna uma questão para uma pesquisa científica, um novo horizonte de leituras surge. A questão se transforma em objeto de saber e começa a "aparecer" em toda parte, inclusive em lugares já muito visitados, em textos já lidos e relidos, lá onde ela ainda não havia sido notada. Isso faz perceber muito rapidamente que muitas das "nossas" questões, ou pelo menos boa parte delas, já haviam sido mencionadas, esboçadas, comentadas, formuladas e analisadas por outros autores, das mais diversas maneiras. Desse modo, como observa Michel de Certeau ([1980] 2014), "malgrado a ficção da página em branco, sempre escrevemos sobre algo escrito" (p.103).

Ao mesmo tempo, essas questões não necessariamente figuram como fundamentais ou centrais nos trabalhos dos autores que lemos. É o caso da questão do cotidiano: apesar de estar presente em muitos trabalhos, nem sempre ela é central, o que faz com que nem sempre seja discutida da maneira aprofundada que desejamos.

A novidade do que aqui escrevo advém de um modo singular de escrever sobre algo escrito, com o desejo de discutir de maneira aprofundada sobre a questão do cotidiano na história das ideias linguísticas, a partir de uma perspectiva discursiva. Trabalho de singularização efetuado sempre ao lado e a partir de outros escritos, em dadas condições de produção, em espaços institucionais determinados, no âmbito da perspectiva teórica adotada, com um objeto e alguns objetivos, instigado por algumas perguntas, no contato/confronto com arquivos, mobilizando e delineando caminhos para análises mais específicas.

Com o Projeto O Cotidiano na História das Ideias Linguísticas do Brasil - CoLHIBri, que venho coordenando no Departamento de 
Linguística do IEL da Unicamp desde 2017, e com a criação do Grupo de Pesquisa no $\mathrm{CNPq}, O$ Cotidiano na História das Ideias Linguísticas, formado em 2018, e coordenado em parceria com Carolina Fedatto, venho buscando desenvolver de maneira mais elaborada a reflexão que aqui apresento sobre a questão do cotidiano ${ }^{3}$.

De uma perspectiva discursiva da história das ideias linguísticas, venho me empenhando em construir uma teorização discursiva sobre essa questão, tomando como ponto de partida os estudos de Michel de Certeau, Michel Pêcheux, Sylvain Auroux e Eni Orlandi. O presente trabalho é um resultado inicial desse empreendimento teórico ${ }^{4}$.

Os estudos de Michel de Certeau sobre a invenção do cotidiano (DE CERTEAU, 1978; [1980] 2014); e DE CERTEAU, GIARD E MAYOL, [1994] 2013) são incontornáveis para a presente reflexão. Eles buscam estudar as práticas cotidianas do homem ordinário que inventam modos de escapar à conformação de uma razão técnica.

Por meio de leituras sobre os trabalhos de Michel de Certeau, a questão do cotidiano também comparece em textos de Michel Pêcheux (GADET e PÊCHEUX ([1981] 2004; PÊCHEUX [1982a] 1990; [1982b] 1998; [1982c], 1997; [1983] 2002). Tais leituras permitem a Pêcheux apontar para a necessidade de "se pôr na escuta as circulações cotidianas, tomadas no tomadas no ordinário do sentido" (PÊCHEUX [1983] 2002, p. 48) para um trabalho sobre as materialidades discursivas.

Nos estudos de história das ideias linguísticas, é importante destacar que a questão do cotidiano comparece para Sylvain Auroux (1989; 1992a; 1992b; [1996] 2001) em relação à produção do saber linguístico, considerado como uma realidade histórica, que é produzida no dia-a-dia, cotidianamente. No trabalho do autor, essa questão está ligada, entre outras coisas, à distinção que ele explora entre os saberes epilinguísticos e os saberes metalinguísticos.

Na obra de Eni Orlandi, é possível encontrar um sem-número de teorizações e análises que tocam e ou mobilizam a questão do cotidiano. Para o presente trabalho, interessa de maneira mais particular explorá-la a partir das relações entre unidade, diversidade e dominação (ORLANDI, 1998) e entre língua imaginária e língua fluida (ORLANDI, 1985; ORLANDI e SOUZA, 1988; ORLANDI, 2009). 
Os diálogos e debates com esses autores estão organizados em três partes, seguidas das considerações finais.

$\mathrm{Na}$ primeira parte, discuto sobre o cotidiano enquanto uma instância na qual uma arte do desvio se efetua, inventando modos de escapar à conformação de uma razão técnica. As resistências que aí se realizam são pensadas em relação a especificidade da constituição do saberes linguísticos no espaço brasileiro, no jogo entre unidade, diversidade, dominação e resistência, por uma relação entre língua imaginária e língua fluida: um percurso em que a arte do desvio à língua imposta acaba transformando essa língua em outra.

$\mathrm{Na}$ parte seguinte, destaco relação entre dominação e resistência, constitutiva em funcionamento no cotidiano abordando o funcionamento da opressão, bem como dos processos de divisão e de hierarquização dos saberes.

$\mathrm{Na}$ terceira parte, me detenho sobre a constituição cotidiana dos saberes para mostrar como, entre as múltiplas coisas-a-saber, os saberes linguísticos especializados ou cotidianos, sempre constituídos pela relação entre ideologia e inconsciente, podem transitar entre $o$ epilinguístico e o metalinguístico. Isso permite compreender como a constituição cotidiana do saber, antes de ser apenas um trabalho de descrição, é desde sempre um trabalho de interpretação.

Por último, apresento minhas considerações finais.

\section{Artes do desvio pelo cotidiano}

Em seu "Une culture très ordinaire", Michel de Certeau (1978) em um diálogo com Benveniste, Freud, Wittgenstein, entre outros autores, mostra como o cotidiano nos constitui e nos atravessa de diversas formas, e como isso está relacionado ao fato de que não é possível escapar ao jogo da linguagem. Uma questão de fundamental importância presente em sua obra pode ser formulada do seguinte modo: $O$ que fazemos com as determinações que nos são impostas? De Certeau vai nos levando a compreender como a chamada cultura "popular" realiza uma arte de fazer que é uma arte do desvio a essas imposições, sendo o cotidiano a instância em que essa arte se dá.

Segundo o autor:

A ordem efetiva das coisas é justamente o que as táticas "populares" desviam para fins 
próprios, sem a ilusão de que ela mude tão cedo. Enquanto é explorada por um poder dominante, ou simplesmente negada por um discurso ideológico, aqui a ordem é colocada em jogo por uma arte. $\mathrm{Na}$ instituição a servir se insinuam assim um estilo de trocas sociais, um estilo de invenções técnicas e um estilo de resistência moral, quer dizer, uma economia do "dom" (de generosidades como revanche), uma estética de "golpes" (de operações de artistas) e uma ética da tenacidade (mil maneiras de recusar à ordem estabelecida o estatuto de lei, de sentido ou de fatalidade). A cultura "popular" seria isto, e não um corpo tomado por estranho, despedaçado a fim de ser exposto, tratado e "citado" por um sistema que redobra, com os objetos, a sua situação que impõe aos vivos (DE CERTEAU, 1978, p. 25 - tradução minha, grifos do autor).

Importante notar as aspas no "popular", que indicam seu questionamento sobre o que uma elite ilustrada reconhece como sendo uma cultura, mas que seria distinta da cultura considerada como erudita. De Certeau salienta aqui e em outras partes de seu texto que pretensão de dizer/saber o que seria essa cultura "popular" é uma forma de dominação que reduz práticas a objetos. Em relação a isso, também vale trazer aqui o que diz o autor:

As instâncias do saber etnológico ou folclórico retêm delas [dessas práticas] os objetos físicos ou linguísticos, etiquetados em lugares de origem e em temas, colocados na vitrine, expostos à leitura e destinados a disfarçar, sob "valores" camponeses oferecidos à edificação ou à curiosidade dos citadinos, a legitimação de uma ordem supostamente imemorial e "natural" por seus conservadores (DE CERTEAU, 1978, p. 25 tradução minha). 
Em outras palavras, é como se os objetos ligados a essas práticas pudessem substituí-las. A conveniência dessa substituição é a dominação que ela produz, que também é uma concessão (Isso também é cultura...) e uma divisão/hierarquização (mas, claro, apenas uma cultura popular) ${ }^{6}$.

Ao longo de suas reflexões, De Certeau ([1980] 2014) vai analisando o que fazemos diante das razões técnicas que pretendem nos conformar quando consumimos, quando lemos, quando assistimos TV, quando contamos histórias, quando moramos, quando cozinhamos, quando caminhamos, quando trabalhamos em uma fábrica ou em uma universidade. Em relação ao espaço universitário, por exemplo, autor vai mostrando de que maneiras, no cotidiano, podemos:

desviar o tempo devido à instituição; fabricar
os objetos textuais que significam uma arte e
solidariedades; jogar esse jogo do
intercâmbio gratuito, mesmo que castigado
pelos patrões e pelos colegas, quando não se
limitam a "fechar os olhos"; inventar os
traçados de conivências e de gestos;
responder com um presente a outro dom;
subverter assim a lei que, na fábrica
científica, coloca o trabalho a serviço da
máquina e, na mesma lógica, aniquila
progressivamente a exigência de criar e a
"obrigação de dar" (DE CERTEAU, [1980]
2014, p. 85 - grifo do autor).

A arte do desvio, nesse sentido, não deixa ileso o campo de saberes de especialistas, produzidos nos espaços mais autorizados e legitimados de nossa sociedade. A produção cotidiana do saber especializado também está sujeita à arte do desvio, uma vez que os especialistas não são máquinas de produzir conhecimento e que o conhecimento não se reduz a razões técnicas.

É interessante notar que essa arte do desvio, em suas diversas manifestações, pode funcionar sob a forma de resistências, semelhantes àquelas definidas por Michel Pêcheux ([1982a] 1990) em relação à língua: 
As resistências: não entender ou entender errado; não "escutar" as ordens; não repetir as litanias ou repeti-las de modo errôneo, falar quando se exige silêncio, falar sua língua como uma língua estrangeira que se domina mal; mudar, desviar, alterar o sentido das palavras e das frases; tomar os enunciados ao pé da letra; deslocar as regras na sintaxe e desestruturar o léxico jogando com as palavras...

E assim começar a se despedir do sentido que reproduz o discurso da dominação, de modo que o irrealizado advenha formando sentido no interior do sem-sentido (p. 17).

Tendo feito essa aproximação inicial entre o que diz De Certeau sobre da arte do desvio e o que diz Pêcheux sobre as resistências, gostaria, agora, de retomar outros textos que trazem reflexões importantes para uma compreensão discursiva das relações entre unidade, diversidade, dominação, resistência, além da domesticação da resistência, que também é uma forma de dominação.

Nesse sentido, vale lembrar a afirmação de Pêcheux ([1978] 1997) de que "não há dominação sem resistência" (p. 304). Este é um dos pontos incontornáveis de sua discussão sobre o assujeitamento na análise de discurso. No mesmo texto, o autor diz:

O lapso e o ato falho (falhas do ritual, bloqueio da ordem ideológica) bem que poderiam ter alguma coisa de muito precisa a ver com esse ponto sempre-já aí, essa origem não detectável da resistência e da revolta: formas de aparição fugidias de alguma coisa "de uma outra ordem", vitórias ínfimas que, no tempo de um relâmpago, colocam em xeque a ideologia dominante tirando partido de seu desequilíbrio (PÊCHEUX, [1978] 1997, p. 301). 
A relação entre dominação e resistência é explorada por Eni Orlandi em diversos textos com diferentes objetos e objetivos. Em Terra à Vista (ORLANDI, 1990), ela é pensada relativamente à constituição da identidade do sujeito brasileiro no processo de colonização no Brasil, que se dá em relação a uma necessidade de domesticação do desconhecido por parte do colonizador, a partir da qual vão sendo produzidas diferentes formas de resistência.

A reflexão da autora se desdobra, em "Ética e Política Linguística" (ORLANDI, 1998), na formulação de três posições distintas para pensar as políticas linguísticas: a da unidade, a da diversidade e a da dominação. São três posições que correspondem a diferentes razões, com princípios éticos diferentes e que estão quase sempre em relação de contradição. Segundo a autora, a análise deve fazer face a essa relação contraditória e não apagá-la. Isso significa considerar que, na relação entre unidade e diversidade, por exemplo, pode haver movimentos de resistência e, ao mesmo tempo, movimentos de absorção, de domesticação da resistência, de dominação.

O exemplo que Orlandi traz do funcionamento da posição da unidade em sua relação com a diversidade é bastante ilustrativo dessa contradição para compreendermos a constituição da língua nacional no espaço brasileiro e a gramatização brasileira do português:

Podemos referir aqui a questão da língua nacional no Brasil como um dos elementos de definição da identidade brasileira. Esta questão leva à consideração da variação (e por aí da diversidade) na medida em que ela pode caracterizar o Brasil como um país distinto de Portugal. Mas, por outro lado, isto se inscreve na constituição da unidade necessária (ou de uma nova unidade) nesse novo espaço que é o Brasil. Assim, os indigenismos, os africanismos, os provincianismos, os regionalismos aparecem como diferenças "domesticadas", enquanto características do Brasil. Em outras palavras, todas as diversidades dos falares $\mathrm{e}$ a diversidade do conjunto das línguas indígenas brasileiras e das línguas africanas faladas no 
Brasil são referidas à unidade da língua nacional. O que há de específico é que essa unidade não é referida ao português de Portugal mas ao do Brasil. A universalidade muda seu eixo, no processo de historicização - que inclui a gramatização do português brasileiro (E. Orlandi e E. Guimarães, 1998) - do lado de cá do Atlântico: o domínio de "nossa" universalidade é o território brasileiro (ORLANDI, 1998, p. 10).

Como podemos notar, há diferenças que vão sendo domesticadas na história das línguas no espaço brasileiro nesses processos, ou seja: a posição da unidade tende a domesticar a diversidade.

Para dar mais visibilidade à relação contraditória entre unidade e diversidade, vale aqui contrastar a descrição desses mesmos processos, mas apontando para efeitos da diversidade sobre a unidade, conforme fazem Orlandi e Guimarães (2001):

A gramatização em um país colonizado trabalha segundo um duplo eixo: o da universalização, o dos deslocamentos. Ter uma gramática, nestas condições, significa ter direito à universalidade. Por outro lado, falar dos "usos variados" é defender uma "outra" língua. Com efeito, uma vez conquistado o direito à unidade, imediatamente recomeça-se a reconhecer as variedades: a influência da língua dos índios, das línguas africanas etc. Este reconhecimento é o próprio da constituição da unidade do português brasileiro (p. 35 - grifos meus).

As reflexões dos autores permitem compreender que a relação entre unidade e diversidade que está em jogo na constituição do português no espaço brasileiro é efeito de um processo de dominação (de domesticação das diferenças), mas que, ainda assim, não deixa de ser um processo de resistência (falar dos "usos variados" é defender "outra língua"). Ou seja, a domesticação das diferenças é um processo de dominação da diversidade para a constituição de uma unidade 
linguística nacional, ao mesmo tempo em que não deixa de ser um processo de resistência que marca uma diferença linguística, na unidade, pela variação, com Portugal.

A partir disso, é possível observar que as relações entre unidade, diversidade, dominação e resistência não podem ser isoladas, classificadas ou contabilizadas, pois elas não são transparentes e nem identificáveis de uma vez por todas. Ao lado disso, é importante enfatizar que há sempre determinações que presidem essas relações tensas e contraditórias, mas também há pontos de falha indetermináveis nessas determinações, o que significa que elas não podem ser pensadas em termos de determinismo. Do mesmo modo, embora devam ser pensadas sempre em relação a esses pontos de falha indetermináveis, essas tensões e contradições não são aleatórias e, por isso, não podem ser pensadas em termos de relativismo.

Para compreender a dimensão da complexidade das relações é preciso que a análise leve em conta suas condições de produção, sempre considerando a historicidade das línguas e dos saberes linguísticos em contato/confronto. $\mathrm{E}$ isso, no caso da história brasileira, implica ter em vista os efeitos de uma diferença primordial entre os modos pelos quais os contatos/confrontos entre as línguas significam relativamente à memória ocidental e suas instituições ${ }^{7}$.

A partir disso e, inspirada na questão que permeia a obra de De Certeau - $O$ que fazemos com as determinações que nos são impostas? - uma questão mais próxima dos objetivos deste trabalho é: O que fazemos com a língua que nos foi imposta (de Portugal)? Ao consideramos as discussões de Orlandi e Guimarães mencionadas, é possível dizer que transformamos essa língua em outra. Esse processo de transformação da língua em outra é aqui considerado tendo em vista relação entre o especialista, o todos e o qualquer $u m^{8} \mathrm{em}$ diferentes momentos da história de constituição de saberes linguísticos no Brasil.

A reflexão sobre a arte do desvio de transformar em outra a língua que nos é imposta pode ser pensada de maneira interessante a partir da distinção entre língua imaginária e língua fluida de Orlandi (1985), Orlandi e Souza (1988) e Orlandi (2009).

As reflexões de Orlandi e Souza (1988) trazem um questionamento sobre a língua enquanto o objeto da observação do analista e o instrumento (método) a partir do qual se observa o objeto, que é 
sempre uma metalinguagem. As autoras observam que, por um jogo de espelhos entre objeto e método, o analista pode não se dar conta do efeito da metalinguagem sobre o objeto língua. A metalinguagem transforma a língua em um artefato, em uma língua imaginária, "a que os analistas fixam na sua sistematização", diferente da língua fluida, que está em constante movimento, e "que não pode ser contida no arcabouço dos sistemas e fórmulas” (p. 34).

Em Orlandi (2009), a autora salienta que o trabalho de análise com a língua em funcionamento é um trabalho com a relação tensa e contraditória entre língua imaginária e língua fluida (p. 19). Isso é importante justamente porque o analista nunca conseguirá trabalhar apenas com a língua fluida, já que ele não prescinde da língua para falar da língua, ou seja, ele não prescinde de uma metalinguagem. Desse modo, quando pensamos a constituição dos saberes linguísticos na história, podemos dizer que seu processo envolve a construção de metalinguagens (línguas imaginárias) e o que sempre escapa a essas metalinguagens (a língua fluida).

Tendo isso em vista, uma pergunta mais específica que vem me acompanhando é: $O$ que fazemos com a língua imaginária frente a língua fluida? Com essa pergunta, venho buscando estudar de que modo, em nosso dia-a-dia, nos desviamos da língua imaginária que nos é imposta pela gramática. A despeito das determinações que a gramática impõe, a língua flui em nós.

Tomada, aqui, como uma prática discursiva e, desse modo, como não transparente para o sujeito, a arte do desvio funciona como uma

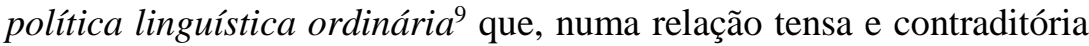
entre a língua imaginária e a língua fluida, torna possível a produção de saberes linguísticos cotidianos para além e para aquém dos saberes linguísticos de especialistas.

\section{Opressão, divisões e hierarquizações}

É importante destacar que a arte do desvio pelo cotidiano não é pensada apenas enquanto resistência, mas sim por uma relação entre dominação e resistência. Produzida pela língua e/ou por outras práticas simbólicas, a arte do desvio também pode funcionar de modo a (re)produzir formas de autoritarismo. Para avançar nessa reflexão, vale trazer aqui a citação que De Certeau faz das palavras de Paul Leuilliot sobre o cotidiano enquanto opressão: 
O cotidiano é aquilo que nos é dado cada dia (ou que nos cabe em partilha), nos pressiona dia após dia, nos oprime, pois existe uma opressão presente. Todo dia, pela manhã, aquilo que assumimos, ao despertar, é o peso da vida, a dificuldade de viver, ou de viver nesta ou noutra condição, com esta fadiga, com este desejo (Paul Leuilliot, 1977, apud DE CERTEAU, [1994] 2013, p. 31 - itálico do texto $)^{10}$.

Essas palavras também fazem lembrar o que a jornalista Eliane Brum $(2017,2019)$ chama de cotidiano de exceção em suas análises sobre os (des)acontecimentos que vêm sobressaltando a vida política brasileira nos últimos anos. Vale aqui chamar a atenção para um dos vieses desse cotidiano de exceção: a proliferação de discursos visando deslegitimar campos de saberes, principalmente aqueles produzidos em universidades. São discursos, cada vez mais corriqueiros, destinados não à implementação de debates críticos sobre o saber e seus poderes, mas a distorcer, deformar, corroer e, em última instância, aniquilar determinados tipos de saber, suas instituições e a parcela da sociedade que o produz ${ }^{11}$.

Nessa conjuntura de (des)acontecimentos políticos, o surgimento da pandemia do novo coronavírus fez emergir outros confrontos discursivos (PÊCHEUX, [1983] 2002), como o que vem sendo catalisado pela expressão "novo normal", em relação a inúmeras práticas sociais, incluindo aí práticas relativas a produção de saber nas instituições escolares ${ }^{12}$.

Certamente, novas formas de resistência também vão emergindo em nosso dia-a-dia em meio a essas conjunturas. Mas seu acontecimento nos discursos cotidianos, assim como na dominação, é sempre e ao mesmo tempo perfeitamente transparente $\mathrm{e}$ profundamente opaco (PÊCHEUX, [1983] 2002).

Pensar o cotidiano como opressão também permite estabelecer relações de sentido com o tédio, a irrelevância e a insignificância dos acontecimentos. Esse sentido de cotidiano tem uma presença/ausência interessante em narrativas tradicionais da história do conhecimento 
que costumam realçar as descobertas científicas geralmente atribuídas a personagens geniais.

Um dos efeitos desse modo de fazer história é que ele coloca em jogo não apenas uma hierarquização de saberes, mas também uma divisão sobre o que seria e o que não seria o saber. Divisão e hierarquização que, nas atuais condições de produção do conhecimento, significam o saber científico como do domínio do extraordinário, ao mesmo tempo em que significam determinados tipos de saber e tudo o que é considerado como não saber como do domínio do ordinário. Em outras palavras, nessas narrativas, a produção do conhecimento - ou o momento em que a descoberta se dá - pertenceria ao domínio dos acontecimentos extraordinários: estaria fora da ordem do cotidiano. Invenção, opressão, resistência e dominação caminham juntas, cotidianamente.

Diretamente ligado a esses sentidos de cotidiano em relação ao saber, há outro, também interessante deixar mais destacado aqui: aquele que a cientificidade vem buscando descrever, organizar e dominar e que pode ser referido por nomes como senso-comum, saberes populares ou sabedoria popular. Trata-se de outra maneira de reforçar a divisão e a hierarquização de saberes, de modo a tentar manter, também aqui, uma distância entre o saber que geralmente significa como pertencente ao domínio do cotidiano e o saber que geralmente significa como especializado e, portanto, como estando fora desse domínio do cotidiano. Mas nenhum deles escapa à ordem do cotidiano.

\section{Ideologia, inconsciente, saberes}

Muitas nuances poderiam ser exploradas entre os sentidos de cotidiano em relação ao saber, aqui brevemente comentados, além de inúmeros outros sentidos para essa palavra. Destacarei aqui apenas mais um, que é a consideração de que os saberes são produzidos cotidianamente. Essa perspectiva é fundamental para trabalhos em História das Ideias Linguísticas que se interessam em explorar, a partir de diferentes materiais, vestígios do processo cotidiano de constituição do saber. Considerar que os saberes são produzidos cotidianamente possibilita explorar os efeitos de fronteira que vão delimitando diferentes tipos de saber, além de compreender de que 
maneiras saberes linguísticos cotidianos e saberes de especialistas vão se construindo de maneira intrincada.

$\mathrm{Na}$ introdução que S. Auroux faz para o a obra Histoire des Idees Linguistiques (Auroux, 1989), podemos apreciar uma passagem clássica, retomada um sem-número de vezes por diversos pesquisadores, sobre o saber como algo produzido no dia-a-dia, cotidianamente. É interessante notar que, na versão brasileira desta introdução, publicada em $A$ revolução tecnológica da gramatização (Auroux, 1992), a expressão "de la constitution au jour le jour du savoir" é traduzida como "da constituição cotidiana do saber". Cito aqui a versão brasileira:

Todo conhecimento é uma realidade histórica, sendo que seu modo de existência real não é a atemporalidade ideal da ordem lógica do desfraldamento do verdadeiro, mas a temporalidade ramificada da constituição cotidiana do saber (AUROUX, 1992, p. 11).

Vemos aí o cotidiano enquanto temporalidade ramificada da constituição do saber, em oposição a um modo de considerar o saber a partir de uma temporalidade ideal da ordem lógica do desenvolvimento do verdadeiro. A compreensão do que o autor chama de realidade histórica, se pensada de uma perspectiva discursiva da história das ideias linguísticas, faz com que tenhamos que realizar uma série de deslocamentos teóricos. Para uma história das ideias linguísticas empreendida da perspectiva da análise de discurso, é preciso percorrer a materialidade discursiva que preside os processos de constituição do saber.

As teses de Auroux sobre as revoluções tecnolinguísticas da escrita e da gramatização estão fundamentadas em uma posição a partir da qual a constituição dos saberes linguísticos se daria pela relação entre dois tipos de saber: o saber epilinguístico e o saber metalinguístico. A partir de um diálogo com Antoine Culioli (1968a, 1968b) sobre a noção de atividade epilinguística, Auroux define o saber epilinguístico como "o saber inconsciente que todo locutor possui de sua língua e da natureza da linguagem” (AUROUX, 1992b, p. 33). Em relação a essa definição, ele acrescenta: 
Assumimos que inconsciente significa não representado; em outras palavras, se esse saber é inconsciente como saber (não sabemos como sabemos) é porque não dispomos de meio (metalinguagem ou sistema de notação) para falar da linguagem. Ainda que não-representado enquanto tal, esse saber pode (e deve) se manipular sob forma de relações conscientes com seu objeto (no sentido da correção, dos jogos de linguagem, etc.): esta manifestação é o que chamamos consciência epilinguística (...) (AUROUX, 1992b, p. 33).

Dessa maneira, podemos notar que, no trabalho do autor, a definição de epilinguístico está ligada a um sentido de inconsciente como não representado, mas passível de manipulação sob a forma de relações conscientes com o seu objeto. Ao lado disso, a definição de metalinguístico está ligada a um sentido de consciente como representado e manipulado. A diferença, para Auroux, é que o saber metalinguístico é um tipo de saber particular, cuja representação é sistematizada $^{13}$. Desse modo, há uma relação de sinonímia entre inconsciente como não representado e consciente como representado e manipulado, que produz um efeito de que teríamos controle sobre nosso dizer ao construir um saber metalinguístico.

Assim, em sua obra, é necessário falar do que existia como saber linguístico antes mesmo da existência de gramáticas, dicionários e outros instrumentos linguísticos. É necessário, também, construir a hipótese de um limite entre o epilinguístico e o metalinguístico ao mesmo tempo em que "é preciso antes considerar a relação entre os dois como um continuum" (p. 33) uma vez que, "no domínio propriamente gramatical, ainda hoje nem sempre existe realmente solução de continuidade" (p. 16) entre esses dois saberes. Isso porque, para Auroux, o saber linguístico tem uma especificidade: “o próprio do saber linguístico" é outra coisa, diferente d"o saber das coisas naturais" $" 14$.

É de outro modo que compreendo essas noções a partir uma perspectiva discursiva da História das Ideias Linguísticas. Nesse 
sentido, gostaria de retomar a afirmação de Michel Pêcheux ([1975] 1997) de que há uma articulação entre ideologia e inconsciente que constitui o sujeito e o sentido. A respeito disso, o autor salienta que:

o caráter comum das estruturas-
funcionamentos designadas, respectivamente,
como ideologia e inconsciente é o de
dissimular sua própria existência no interior
mesmo do seu funcionamento, produzindo
um tecido de evidências "subjetivas",
devendo entender-se este último adjetivo não
como "que afetam o sujeito", mas "nas quais
se constitui o sujeito" (PÊCHEUX, ([1975]
1997, p. 152-153).

Desse modo, de uma posição discursiva, a "consciência", enquanto controle do que se diz, não é senão um efeito da relação material das estruturas-funcionamento da ideologia e do inconsciente. Há, portanto, um efeito de consciência, sustentado no efeito de evidência do sujeito e do sentido. Tanto o epilinguístico quanto o metalinguístico são constituídos por esse efeito de consciência.

Tendo isso em vista, é importante acrescentar que o que o autor chama de representação, manipulação e, consequentemente, de saber também não são práticas transparentes para o sujeito (embora funcionem e signifiquem sob a transparência produzida por esse efeito de consciência), já que são atravessados pela linguagem e pela língua, que também são opacas e não transparentes.

Assim, o efeito de consciência presente na produção de um saber metalinguístico - Eu sei do que estou falando - é atravessado pela materialidade linguística-histórica, pelo discurso, na relação entre inconsciente e ideologia, não sendo, portanto, nenhuma garantia de que se sabe do que se fala.

A esse respeito, vale lembrar aqui a reflexões de Michel Pêcheux ([1983] 2002) sobre as coisas-a-saber. Segundo o autor, elas são múltiplas, são produzidas pelas múltiplas urgências do cotidiano e representam "tudo o que arrisca faltar à felicidade (e no limite à simples sobrevida biológica) do "sujeito pragmático"” (p. 34). Segundo o autor, essas múltiplas urgências do cotidiano encontram no 
Estado e nas instituições polos privilegiados de resposta a esta necessidade ou a essa demanda de saber.

$\mathrm{O}$ autor lembra que há coisas-a-saber próprias do espaço da matriz científica da física. E, também, que há coisas-a-saber próprias das disciplinas de interpretação, funcionando nos espaços científicos concernentes ao real sócio-histórico, com um sistema estrutural não análogo à coerência conceptual-experimental galileana. E lembra ainda que esses diferentes tipos de coisas-a-saber são coexistentes com "um outro tipo de saber, que não se reduz à ordem das "coisas-asaber" ou a um tecido de tais coisas". É "um saber que não se transmite, não se aprende, não se ensina, e que, no entanto, existe produzindo efeitos" (PÊCHEUX, ([1983] 2002, p. 43). Ou seja, o que sustenta as evidências de saber o que quer que seja é justamente o efeito da ideologia, que funciona pelo inconsciente.

Pêcheux acrescenta também que "“as coisas a saber" coexistem assim com objetos a propósito dos quais ninguém pode estar seguro de "saber do que se fala"” (PÊCHEUX, ([1983] 2002, p. 55). Os saberes - tanto os diferentes tipos de coisas-a-saber como o saber composto por objetos a propósito dos quais ninguém pode estar seguro de saber do que se fala - se constituem na pluralidade contraditória das filiações históricas nos mais diferentes níveis: "tanto nos segredos da esfera familiar "privada" quanto no nível "público" das instituições e dos aparelhos de Estado" (PÊCHEUX, ([1983] 2002, p. 55).

Mas a história dos saberes - dos mais diversos tipos, nos mais diferentes espaços - passa incontornavelmente pela história das ciências, na qual, a busca pela ciência régia tem sido imperiosa. Segundo Pêcheux:

(...) o fantasma da ciência régia é justamente o que vem, em todos os níveis, negar esse equívoco [da coexistência das coisas-a-saber com outros saberes que se constituem na pluralidade das filiações históricas], dando a ilusão que sempre se pode saber do que se fala, isto é, se me compreendem bem, negando o ato de interpretação no próprio momento em que ele aparece" (PÊCHEUX, [1983] 2002, p. 55 - grifos meus). 
A ilusão de que sempre se pode saber do que se fala é a ilusão de todas as coisas-a-saber. O processo pelo qual as condições materiais de existência produzem alguma coisa-a-saber é um processo de discursivização, cujo efeito é o de que se já se soubesse sobre a coisa toda. Por essa razão, como se trata de uma ilusão, ou melhor, um efeito produzido pela relação entre ideologia e inconsciente, qualquer coisa-a-saber é um objeto a propósito do qual ninguém conseguirá jamais saber completamente do [objeto/coisa] que se fala.

A impossibilidade de atingir a realidade empírica das coisas passa incontornavelmente pelo impossível do real da língua. E o real da língua, escreve Pêcheux ([1983] 2002) é "o fato linguístico do equívoco como fato estrutural implicado pela ordem do simbólico". É isso que permite afirmar que "o humor e o traço poético não são o domingo do pensamento" (p. 53) e, consequentemente, que o humor e o traço poético afetam, embora não do mesmo modo, tanto as formulações irremediavelmente equívocas, como as proposições de aparência logicamente estável.

Há ainda mais um aspecto interessante a deslocar da reflexão sobre relação entre o epilinguístico e o metalinguístico dos estudos de Auroux. Em outro trabalho do autor (AUROUX, [1996] 2001), é possível encontrar um desdobramento de suas reflexões a respeito dessa distinção, articuladas ao papel da escrita e da gramatização no desenvolvimento das ciências da linguagem. Essas reflexões são interessantes porque colocam em cena um modo de pensar a questão da descrição que também é importante discutir aqui.

Ao pensar sobre o papel da escrita no desenvolvimento das ciências da linguagem, a descrição é tomada por Auroux a lado da tematização como algo bem diferente de uma simples transposição. Segundo o autor, a transposição da cadeia falada pela escrita é um equivalente à fala. A transposição permite a ultrapassagem da linearidade da fala para a bidimensionalidade do suporte gráfico. Essa bidimensionalidade permite o desenvolvimento de uma razão gráfica $^{15}$ que, por sua vez, leva ao desenvolvimento do saber metalinguístico. O desenvolvimento da razão gráfica é, então, para ele, um processo de descrição e tematização que explicita as propriedades da linguagem. Faz parte desse desenvolvimento a invenção de paradigmas (divisão das classes de palavras, conjugação, declinação etc.). Um paradigma, segundo o autor, "não representa a 
fala, ele descreve condições de seu funcionamento, utilizando as duas dimensões da tabela." (AUROUX, [1996] 2001, p. 90, 91).

As reflexões do autor contribuem enormemente e em detalhes, como os rapidamente apontados aqui, para a compreensão de como as ciências da linguagem são tributárias das revoluções tecnológicas da escrita e da gramatização. Nesse percurso pela história dos saberes linguísticos, a noção de descrição permanece, entretanto, circunscrita como uma prática que seria técnica, cognitiva e social.

A reflexão de Auroux sobre a passagem do que se escreve para o que se descreve não leva em conta os efeitos das discursividades sobre os saberes nas condições de produção sobre esses saberes, ou seja, não considera algo fundamental: as condições de produção do discurso, incluindo aí do discurso sobre (ORLANDI, 1990), que determinam a constituição dos saberes, e que envolvem a consideração da materialidade da língua na relação entre inconsciente e ideologia. Para uma história das ideias linguísticas discursiva, considerar essas condições de produção e a materialidade da língua discursivamente é imprescindível, assim como o que interessa para as análises, nessa perspectiva, é justamente explorar os efeitos discursivos da passagem do escrever para o descrever enquanto processos de interpretação ${ }^{16}$.

A respeito disso, lembro a discussão de Pêcheux ([1983] 2002) sobre a relação entre descrição e interpretação que problematiza justamente a questão da metalinguagem:

A consequência do que precede é que toda descrição - quer se trate da descrição de objetos ou de acontecimentos ou de um arranjo discursivo-textual não muda nada, a partir do momento em que nos prendemos firmemente ao fato de que "não há metalinguagem" - está intrinsecamente exposta ao equívoco da língua (PÊCHEUX, [1983] 2002, p. 53).

A partir disso, é possível compreender, de uma perspectiva discursiva, que a não existência de uma solução de continuidade entre o epilinguístico e o metalinguístico reside no fato de que o real da língua é impossível de ser atingido: não há metalinguagem possível - 
que possa falar da linguagem, como se a linguagem fosse transparente - que alcance esse real ${ }^{17}$.

Dizer que não há metalinguagem não significa de modo algum desprezar a noção de metalinguagem e seus efeitos, pois isso seria contornar o equívoco próprio da história da constituição dos saberes linguísticos. Construir um objeto de saber é recortá-lo e discipliná-lo, é construir para ele uma transparência imaginária. De uma perspectiva discursiva, o saber metalinguístico não deixa de produzir uma descrição, mas, ao fazê-lo, ele constrói um efeito de verdade e de transparência, ao mesmo tempo em que, em muitas áreas, tende a apagar o fato de que produz também uma interpretação. Da posição discursiva, o que não pode ser desconsiderado é o papel da interpretação na descrição, que se dá, na história, pela relação entre língua e discurso, entre estrutura e acontecimento.

Nesse sentido, diria que o saber metalinguístico significa enquanto tal por um efeito de consciência, que é um efeito ideológico particular: o de que se (re)produz/domina esse saber. Quanto ao saber epilinguístico, diria que ele pode significar por esse tipo de efeito de consciência ou apenas por outro efeito ideológico mais elementar: aquele que se (re)produz pela memória discursiva, como uma experiência histórica, um saber discursivo, uma vivência de sentidos (ORLANDI, 2008).

Cabe ressaltar que, para o percurso dos estudos de Auroux, não é o saber metalinguístico necessariamente que importa, mas de que modo esse tipo de saber e (não outro, como o epilinguístico) pôde ser, na constituição cotidiana do saber, cada vez mais sistematizado e aprofundado, levando ao desenvolvimento das ciências da linguagem - que abrange as revoluções tecnológicas da escrita, da gramatização e, mais recentemente, da mecanização da linguagem pela informática.

Para a perspectiva de meu trabalho, os objetivos são outros. É justamente a questão da não-sistematização dos saberes linguísticos, sejam eles epilinguísticos ou metalinguísticos, que me interessa. Com isso, considero importante salientar que a noção de saber linguístico cotidiano não se recobre pela noção de saber epilinguístico. Os saberes linguísticos cotidianos podem ser epilinguísticos ou metalinguísticos - tal como os redefini aqui, enquanto efeitos ideológicos. 


\section{Considerações finais}

Este foi o percurso de reflexões pela questão do cotidiano que desenhei aqui em relação aos saberes linguísticos de uma perspectiva discursiva na história das ideias linguísticas. Certamente, há vários outros sentidos e funcionamentos a explorar.

Aqui, pude discutir como os saberes linguísticos são produzidos cotidianamente. Seja por especialistas, seja pelo todos, seja pelo qualquer um. Não da mesma maneira, embora possam reproduzir, diferentemente, as mesmas discursividades. Isso porque, ao produzirem discursos sobre as línguas em contato/confronto, que vão sendo significadas e praticadas em torno dos princípios da unidade, da diversidade e da dominação, precisam lidar com a relação contraditória entre a língua imaginária e a língua fluida.

A despeito do desejo que nos impele a perseguir novas metalinguagens que deem conta dessa língua inatingível, há algo que sempre escapa e flui por outros espaços, fazendo sentido em nosso cotidiano. A despeito do desejo que nos impele a esquecer o que nossas metalinguagens não conseguem descrever, há algo que sempre retorna e resiste porque não deixa de fluir em outros espaços, fazendo sentido. Qualquer que seja o saber, a língua imposta nunca será completamente realizada. Ela está eternamente sujeita a mil e uma artes do desvio e esse real insiste por todos os lados.

\section{Referências bibliográficas}

AUROUX, Sylvain. Introduction. In: Auroux, Sylvain (Dir.), Histoire des idées linguistiques, Tome. 1 La naissance des métalangages en Orient et en Occident. Bruxelles: Pierre Mardaga, 1989.

AUROUX, Sylvain. Introduction. Le processus de grammatization et ses enjeux. In: Sylvain Auroux (Dir.) Histoire des idées linguistiques. Tome 2. Le développement de la grammaire occidentale. Liège: Pierre Madarga, 1992a.

AUROUX, Sylvain. A Revolução Tecnológica da Gramatização. Campinas: Editora da Unicamp, 1992 b.

AUROUX, Sylvain (com a colaboração de Jacques Deschamps, Djamel Kouloughli). A filosofia da linguagem. Campinas: Editora da Unicamp, 2001.

BRUM, Eliane. Cotidiano de Exceção. El País. Opinião, 2017. Disponível 
https://brasil.elpais.com/brasil/2017/05/29/opinion/1496068623 6442 64.html. Acesso: 30 jul 2020.

BRUM, Eliane. Quem mandou matar Marielle? E por quê? El País. Opinião, 2019. Disponível em: https://brasil.elpais.com/brasil/2019/03/13/opinion/15524850398979 63.html. Acesso: 30 jul 2020.

COLOMBAT, Bernard; FOURNIER, Jean-Marie; PUECH, Christian. Histoire des idées sur le langage et les langues. Paris, Klincksieck, 2010.

CULIOLI, Antoine. A propos du genre en anglais contemporain. In: Les langues modernes, 3. Paris: Didier Erudition, 1968. p. 326-334. CULIOLI, Antoine. La formalisation en linguistique. In: Cahiers pour analyse, 9. Paris: Cercle d'Epistémologie de l'Ecole Normale Supérieure, 1968. p. 106-117.

DE CERTEAU, Michel. Une culture très ordinaire. Esprit. Changer la culture et la politique, n. 22. Paris, 1978.

DE CERTEAU, Michel. A invenção do cotidiano. 1. Artes de fazer. Petrópolis: Vozes, 2014, 22ed.

DE CERTEAU, Michel; GIARD, Luce; MAYOL, Pierre. A invenção do cotidiano. 2. Morar, cozinhar. Petrópolis: Vozes, 2013, 12ed.

DESCICLOPÉDIA. Página principal. Disponível em: http://desciclopedia.org/wiki/Página_principal. Acesso: 30 jul 2020.

ENCICLOPÉDIA ABRIL. Prezado Leitor. São Paulo: Abril Cultural, Tomo I, 2 ed., 1976.

FERREIRA, Ana Cláudia Fernandes. As coisas-a-saber sobre uma cidade na Wikipédia e na Desciclopédia: Pouso Alegre entre edifícios e buracos. Rua, n. 18, v. 2. Campinas: Labeurb/Unicamp, 2012. p. 3559.

FERREIRA, Ana Cláudia Fernandes; FARIA, Joelma Pereira de. Dialetos/Línguas do Brasil na Desciclopédia. Rua, n. 22, v. 2. Campinas: Labeurb/Nudecri/Unicamp, 2016. p. 593-613.

GADET, Françoise; PÊCHEUX, Michel. A língua inatingível: o discurso na história da linguística. Campinas: Pontes, 2004.

GODDY, Jack. The Domestication of the Savage Mind. Oxford University Press; La raison graphique. Paris, Minuit, 1979.

ORLANDI, Eni. Língua imaginária e língua fluida. Seminário IEL/Unicamp, 1985. 
ORLANDI, Eni. Terra à Vista. São Paulo, Cortez; Campinas: Editora da Unicamp, 1990.

ORLANDI, Eni. As Formas do Silêncio: no movimento dos sentidos. Campinas: Editora da Unicamp, 2007, 6ed.

ORLANDI, Eni. Ética e Política Linguística. Línguas e Instrumentos Linguísticos, 1. Campinas: Pontes; Projeto História das Ideias Linguísticas no Brasil, 1998.

ORLANDI, Eni. Educação em direitos humanos: um discurso. Educação em Direitos Humanos: fundamentos teórico-metodológicos. In: Silveira, Rosa Maria Godoy e outros. (Orgs.). Educação em direitos humanos: fundamentos teórico-metodológicos. João Pessoa: Editora Universitária, 2008. p. 295-311.

ORLANDI, Eni. Língua brasileira e outras histórias: discurso sobre a língua e ensino no Brasil. Campinas: RG, 2009.

ORLANDI, Eni; SOUZA, Tania Clemente. Língua imaginária e língua fluida: dois métodos de trabalho com a linguagem. In: Eni Orlandi (Org.). Política linguística na América Latina. Campinas: Pontes, 1988. p. 27-40.

ORLANDI, Eni; GUIMARÃES, Eduardo. Formação de um Espaço de Produção Linguística: a gramática no Brasil. In: Orlandi, Eni (Org.) História das Ideias Linguísticas: Construção do Saber Metalinguístico e Constituição da Língua Nacional. Cáceres: Unemat/Campinas: Pontes, 2001, 21-38.

PÊCHEUX, Michel. Semântica e Discurso. Uma Crítica à Afirmação do Óbvio. Campinas: Editora da Unicamp, 1997.

PÊCHEUX, Michel. Só há causa daquilo que falha ou o inverno político francês: início de uma retificação. In: Semântica e Discurso. Uma Crítica à Afirmação do Óbvio. Campinas: Editora da Unicamp, 1997.

PÊCHEUX, Michel. Delimitações, inversões, deslocamentos. Cadernos de Estudos Linguísticos, 19. Campinas: IEL/Unicamp, 1990.

PÊCHEUX, Michel. Sobre a (Des-)construção das teorias linguísticas. Línguas e Instrumentos Linguísticos, v. 2. Campinas: Pontes, 1998. PÊCHEUX, Michel. Ler o Arquivo Hoje. In: Orlandi, Eni (Org.) Gestos de Leitura. Da História no Discurso. Campinas: Editora da Unicamp, 1997, 2 ed. 


\section{PÊCHEUX, Michel. O discurso: estrutura ou acontecimento.}

Campinas: Pontes, 2002. WIKIPÉDIA. Página Principal. Disponível em: http://pt.wikipedia.org/wiki/Wikipédia:Página_principal. Acesso: 30 jul 2020.

\section{Notas}

* Docente do Departamento de Linguística do Instituto de Estudos da Linguagem da Universidade Estadual de Campinas.

${ }^{1} \mathrm{O}$ que chamo aqui de saberes especializados são esses saberes historicamente produzidos em instituições que os autorizam e legitimam em razão de essas instituições significarem enquanto os lugares de produção de conhecimento (hoje, notadamente, escolas, universidades, academias, associações científicas e centros de pesquisa, por exemplo). Nesse sentido, saberes especializados são aqui compreendidos como saberes produzidos por especialistas dessas instituições, no âmbito de domínios como os da gramática, da linguística e da literatura, por exemplo.

${ }^{2}$ Um primeiro esboço de reflexão que me levou, posteriormente, a propor essa noção foi formulado em meu Projeto de Pesquisa Uma história das ideias entre a (des)construção e a (re-)invenção dos saberes linguísticos, elaborado para o Concurso público na área de História das Ideias Linguísticas do Departamento de Linguística do Instituto de Estudos da Linguagem da Unicamp, em 2015. Depois, em Ferreira e Faria (2016), em um estudo sobre sentidos de dialetos/línguas do Brasil na Desciclopédia, a noção de saber linguístico cotidiano comparece esboçada como "um saber que suscita interesse e curiosidade, e que é movido por afetos, pelo humor, por conflitos, por disputas etc. Um saber linguístico que não é uno ou unívoco, mas que também não é aleatório. Ele está relacionado a saberes já construídos, legitimados ou não, teorizados ou deixados de lado pelas teorias. Saberes que circulam e que significam, para aquém e para além do espaço da ciência. (p. 594). A partir desse percurso, pude elaborar o artigo "Saberes linguísticos cotidianos", ainda inédito, que avança na teorização dessa noção.

${ }^{3}$ O Projeto CoLHIBri (https://www.colhibri.site) e o Grupo de Pesquisa no CNPq (http://dgp.cnpq.br/dgp/espelhogrupo/4262082783774510) contam com a participação de alunos e pesquisadores de diversas instituições brasileiras. São três as linhas de pesquisa do projeto e do grupo: A noção de cotidiano; Formas de saber linguístico no cotidiano brasileiro; e Ensino e produção de conhecimento no cotidiano. As reflexões deste trabalho se voltam mais fortemente para a primeira linha de pesquisa sem, no entanto, deixar de considerar aspectos da segunda e da terceira.

${ }^{4}$ A questão do cotidiano foi e é tema de inúmeras pesquisas e não seria possível apresentar aqui um recenseamento de toda a produção sobre o tema. Na descrição da linha de pesquisa $A$ noção de cotidiano, do site do projeto CoLHIBri, faço uma menção, também sem uma pretensão exaustividade, a um conjunto mais abrangente de textos que trabalha(ra)m direta ou indiretamente com a questão do cotidiano em 
áreas mais ligadas a perspectiva teórica de meu trabalho. Essa descrição está disponível no link: https://www.colhibri.site/a-nocao-de-cotidiano.

5 Texto publicado pela revista Esprit, em 1978 e que depois passou a integrar seu famoso L'invention du quotidien, de 1980, cuja primeira edição brasileira saiu em 1990. Preferi fazer referência à publicação de 1978 em razão da possibilidade de realizar uma tradução independente e escolher outras traduções para determinadas palavras, de modo a preservar detalhes que considero relevantes. Por não ter em mãos outros capítulos que se encontram nas versões francesas do livro, em seus dois volumes, farei, mais adiante, referência às versões brasileiras, sendo o volume I a vigésima segunda edição, de 2014, e o volume II a décima segunda edição, de 2013.

${ }^{6}$ Nesse sentido, cabe destacar que minhas reflexões sobre o cotidiano, notadamente pelo desenvolvimento da noção de saberes linguísticos cotidianos, se afastam do que tem sido genericamente definido como linguística popular. Segundo B. Colombat, JM. Fournier e C. Puech (2010), linguística popular é um termo relativamente consagrado, embora não seja imediatamente claro. No meu entender, o termo linguística popular acaba por (re)produzir uma divisão entre o que seria localizável no domínio de saberes especializados (eruditos) e o que não seria localizável nesse domínio (popular). De maneira bem diferente, a noção de saberes linguísticos cotidianos toma o linguístico como concernente à língua e não propriamente à ciência linguística. A noção de saberes linguísticos cotidianos também permite que eu me debruce sobre uma questão que considero muito cara: as relações tensas e contraditórias entre domínios especializados ligados a instituições do saber que os autorizam e legitimam (como os domínios da gramática, da linguística e da literatura) e saberes produzidos em outros espaços, muitas vezes sem nome, e que os domínios especializados ora colocam para fora, ora tentam integrar.

7 A esse respeito, vale lembrar o que dizem Orlandi e Guimarães (2001): "A ambivalência do processo de unificação do português brasileiro mostra bem, no jogo entre unidade/diversidade, o jogo da relação entre a cultura ocidental, a ciência e sua instituição, e uma cultura não ocidental, dita exótica. A unidade lingüística brasileira é construída a partir de uma língua ocidental instrumentada (e dotada de uma escrita) tendo uma filiação (o latim) que a legitima na sua relação com outras línguas (as línguas latinas) no conjunto lingüístico ocidental (cf. o indo-europeu). Isto já é uma garantia científica para a gramática brasileira que reivindica uma particularidade lingüística gramatical. Dito de outro modo, seu trabalho sobre a língua se inscreve no interior da história científica ocidental. Por outro lado, o fato do português ter esta história seguramente contribuiu para a impossibilidade da língua geral de se apresentar como uma alternativa histórica na construção do país Brasil, uma nação com sua unidade lingüística e sua legitimidade institucional.” (p. 35).

${ }^{8}$ Em Ferreira (2012), pude analisar os efeitos de (des)legitimação do saber e do sujeito do conhecimento em uma análise comparativa da Enciclopédia Abril, impressa, da década de 1970, da Wikipédia e da Desciclopédia. Na Enciclopédia Abril (1976), a parte dedicada ao leitor informa que a publicação contou "com a colaboração de quase uma centena de especialistas altamente categorizados" (p. 1 grifo meu). Já a Wikipédia se define como "a enciclopédia livre que todos podem editar" (Wikipédia, Página principal - grifo meu) e a Desciclopédia se define como "a 
enciclopédia livre de conteúdo e que qualquer um pode editar" (Desciclopédia, Página Principal - grifo meu). Da Abril para a Wikipédia e para a Desciclopédia, há uma passagem do especialista para o todos e para o qualquer um.

9 Venho trabalhando produtivamente com a noção de políticas linguísticas ordinárias enquanto artes do desvio à língua imposta (da gramática, da linguística, da ciência, por ex.) nas disciplinas de História das Ideias Linguísticas e de Políticas Linguísticas que ofereço nos cursos de graduação e de pós-graduação do IEL/Unicamp. Esse trabalho com os alunos me levou a elaborar um artigo, ainda inédito, intitulado de "As mil e uma políticas linguísticas ordinárias". Em 2019, pude apresentar uma síntese dessas reflexões no IX Seminário de Estudos em Análise de Discurso - SEAD, em um trabalho realizado em parceria com Juciele Dias.

${ }^{10}$ Esta citação comparece no Introito, escrito por De Certeau, intitulado de Anais do cotidiano, publicado no segundo volume de A invenção do cotidiano (DE CERTEAU, GIARD E MAYOL, [1994] 2013). Trata-se da citação de um Prefácio escrito por Paul Leuilliot para a obra Por une histoire do quotidien au XIXe siècle en Nivernais, de Guy Thuillier (1977).

11 Ao atacar incessantemente verdades cristalizadas, esses discursos vêm subsidiando a fabricação de "sua própria verdade", um tipo de "pós-verdade" que pretende englobar tudo o que pode interessar aos regimes autoritários e eliminar os sentidos de tudo o que poderia vir a contestar esses regimes.

12 Trata-se de uma impressionante batalha de sentidos sobre o que é ou não aceitável culturalmente como normal. Impressionante porque ela acontece paralelamente a uma política de de-significação, invisibilização e silenciamento (Orlandi, [1992] 2007) de milhares de mortes que pode(ria)m ser evitadas. O cotidiano de exceção da política brasileira vai conduzindo a uma significação da pandemia enquanto fatalidade, uma fatalidade como tantas outras, como algo normal: "E daí? Quer que eu faça o quê?"; "É a vida. Todos nós iremos morrer um dia", "Vou fazer um churrasco" etc. Nessas condições, a pandemia funciona como argumento mais do que propício para que o autoritarismo possa anestesiar o que não consegue asfixiar e, com isso, realizar suas políticas de extermínio e de silenciamento. "O nazismo não recomeçará provavelmente como tal, mas "o ventre ainda é fecundo"”, já observava Pêcheux ([1982a] 1990, p. 19), emendando aí uma menção a uma fala de Brecht. Ontem, os espaços propícios para essas políticas eram campos de concentração e porões de tortura. Hoje, no Brasil, são as próprias cidades, vilas e aldeias, entrecortadas por segregações centenárias, além do espaço digital, que reproduz e reforça essas segregações, além de criar outras.

${ }^{13} \mathrm{O}$ saber metalinguístico é por ele definido mais detalhadamente pelo que designa como três critérios externos: "1. transmissão tradicional específica; 2. ligação com as artes da linguagem; 3. normas de adequação das asserções controladas pelas discussões, e mesmo protocolos explícitos (consistência lógica, exemplos canônicos, fatos)." (p. 34).

${ }^{14} \mathrm{O}$ saber linguístico, para Auroux, resulta da interação entre uma competência ou inteligência humana (uma cognição) e uma competência ou inteligência externa (uma tecnologia), na sociedade (social), no espaço (físico) e na história (tempo). É nesse sentido que o autor diz, em Auroux ([1996] 2001), que a existência dos "instrumentos 
linguísticos se situa não fora das sociedades e em seu lugar, mas em sua própria trama, na constituição de um só tecido indissoluvelmente tecnossocial”' (p. 321).

15 Noção que o autor empresta de Jack Goddy (1979).

16 Discuto mais detidamente sobre essa questão em "Ler (d)escrever e interpretar artefatos", também inédito, a sair em 2020 ou em 2021.

17 Vale notar que Auroux ([1996] 2001) discute a respeito de uma recusa da metalinguagem como algo em comum às teses de Heidegger, Lacan e Wittgenstein, e observa: "O que é visado não é essencialmente a existência da gramática e de sua metalinguagem, mas antes a ideia de que recorrendo (como em Carnap ou em Tarski) a um empilhamento de metalinguagens se pudesse atingir por aí o funcionamento último da linguagem cotidiana: esta não poderia ser objeto sem resto daquelas." (p. 279); e ainda: "Não haverá saber último, que, ao mesmo tempo, represente o funcionamento da linguagem e exprima sua essência" (p. 280). Auroux é sensível a essas discussões, mas o real, para ele, é outro e a língua está fora dele. 